Nig. J. Biotech. Vol. 34 (2017) 89-96

ISSN: 01891731

Available online at

http://www.ajol.info/index.php/njb/index

and www.biotechsocietynigeria.org

DOI: https://dx.doi.org/10.4314/njb.v34i1.12

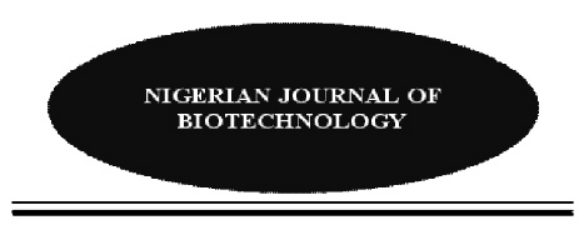

\title{
Molecular characterisation of upland Ofada cultivars and NERICA rice for drought tolerance and their genetic relationships
}

Sakariyawo* ${ }^{1}$, O. S., Adesina ${ }^{2}$, G. D. and Aderibigbe ${ }^{1}$, S. G.

${ }^{1}$ Department of Plant Physiology and Crop Production, Federal University of Agriculture, Abeokuta (FUNAAB), P.M.B. 2240, Alabata, Ogun State, Nigeria

${ }^{2}$ Crop Improvement and Seed Enterprise Development, Centre for Excellence in Agricultural Development and Sustainable Environment,

FuNAAB, P.M.B. 2240, Alabata, Ogun State, Nigeria

Copyright resides with the authors in terms of the Creative Commons License. 4.0.
See http://creativecommons.org/licenses/by/4.0/
Condition of use: The user may copy, distribute, transmit and adapt the work, but must recognize the authors
and the Nigerian Journal of Biotechnology.

\begin{abstract}
Tolerance to water deficit had been reported in Ofada and NERICA rice. The genetic basis of this is unknown. The objective of this experiment was to characterise the genetic basis for tolerance of upland Ofada and NERICA rice to water deficit and determine their genetic relationship. Genomic studies were conducted on upland Ofada rice genotypes (Golden red, straw gold, FUNAABOR 1 and 2) and NERICA rice (NERICA 7 and 8). Among the seven simple sequence repeats markers (RM 212, 36, 3805, 201 and 1115) genetically evaluated two (RM 72 and RM 316) were selected based on their polymorphism (Polymorphic information content and markers index). They both exhibited QTL brt8-12 and QRsf9 in RM 72 and RM 316 respectively, known for drought tolerance. Upland rice cultivars Golden Red, NERICA 8 and NERICA 7 exhibited higher QTL brt8-12 based on their gene ladder more than others on the RM 72 primer. NERICA 7, FUNAABOR 1 and FUNAABOR 2 occupied the highest DNA ladder in the marker RM 316, suggesting the high presence of the QTL QRsf9. Golden Red and NERICA 8 had similar genetic relationship and are better utilised with those of dissimilar sources (Straw Gold) to ensure desirable genetic variation.
\end{abstract}

Keywords: DNA marker, genetic crop improvement, polymorphic information content, Quantitative trait Loci (QTL), Simple Sequence Repeats (SSR),

*Corresponding author: adetanwa@yahoo.co.uk +2347030890180

\section{Introduction}

There is a steady rise in the consumption of rice due to its ease of preparation and changes in demographic profile of the populace (Idris et. al., 2013). There has been a disruption in the demand and supply of rice in most part of Africa with its attendant negative socio-economic implications. Production of rice is found in all agroecologies in Africa. The yield per hectare of lowland rice is more than that of the upland rice. Scarcity of fresh water in most rice production areas of Africa constrained the expansion of lowland rice (Diagne et. al., 2013). This scarcity could be linked to changes in global climate (Belder et al., 2004) and the competing needs for fresh water for both domestic and industrial usage (Bouman, 2007). Cultivation of upland rice provides another alternative in meeting the growing demand for rice in the presence of prevailing production constraints. Fagbade, (2006) reported that upland rice production occupied $50-90 \%$ of cultivated paddies, constituting $30-35 \%$ of National Rice production. Erratic distribution of water remains a major production constraint for the cultivation of upland rice in the rainforest savanna agroecology of Nigeria. Most resourcechallenged farmers could not afford irrigation system; hence they are forced to depend on rainfed production system. The use of drought tolerant upland rice could be another option in the quest to mitigate the negative effects of erratic rainfall distribution in the rainforest savanna agroecology of Nigeria. 
The New Rice for Africa (NERICA) was part of the response provided by Africa Rice Centre to mitigate adverse environmental factors encountered in the continent in the production of rice. NERICA is an interspecific hybrid between Oryza sativa $\times$ Oryza glaberrima (Jones et. al., 1997). The Asian species of O. sativa possesses a higher yield than 0 . glaberrima species native to Africa (Linares, 2002). The later are hardier to adverse environmental conditions. This could have informed the hybridisation process. NERICA rice has been reported to flower earlier than the locally available rice varieties with reasonable yield advantage (Yeo et. al., 1997). It had been reported that Simple Sequence Repeat (SSR) markers are highly polymorphic, abundant, easy to assay with the ability to identify unique allele (Liu et. al., 2016). Polymorphic survey was conducted by Africa Rice Centre on some 70 lines that included parent and sister lines of NERICA using 164 SSR markers. It was reported that $79.3 \%$ of the SSR markers used was polymorphic with the two parental lines of NERICA. The average number of polymorphic marker per chromosome 10.8 , with 0.3-3.4 loci per line frequency of heterozygosity.

The average heterozygosity was 0.4 per line. Parental genome coverage among the 70 lines was $87.4 \%, 6.3 \%$ and $2.7 \%$ for 0 . sativa, 0 . glaberrima and non-parental allele respectively. Among the 18 released NERICA by Africa Rice Centre two distinct groupings were identified; the first group was NERICA 1-7 and the second group was NERICA 8-18. Among the first grouping of NERICA the average introgression of O. glaberrima was significantly higher than that of $O$. sativa. The former had been linked with superior field performance than the former. However the segment of $O$. glaberrima that is related to this superior performance on the field had not been documented. NERICA 7 and 8 were reported to fall into different groupings among the 18 newly released NERICA by Africa Rice Centre (Semagen et. al., 2006). Studies have been conducted on the agronomic and physiological responses of these 18 NERICA rice to water deficit (Nassir et. al., 2017). Significant varietal variation was found on agronomic traits when they were subjected to soil moisture deficit. NERICA 7 and 8 were among those that displayed significant yield advantage under soil water deficit. Despite their distinct groupings the genetic basis for this response could not be ascertained in that study.

In the quest to ameliorate the negative influences of drought on the performance of rice especially in the rainforest savanna agroecology Scientist at the Federal University of Agriculture, Abeokuta have released upland rice varieties; FUNAABOR rice. They were grouped with Ofada rice varieties. Ofada is a generic name given to rice cultivated in the south west part of Nigeria. The genetic identity of this rice cultivar had remained a subject of controversy in the literature. They have been reported to be more robust to negative production influences such as drought (Showemimo et. al., 2011). The genetic basis for their drought tolerance have not been documented neither was their relationship with NERICA rice varieties. Explication of the constitutive-dehydration responsive QTL in these upland rice genotypes would aid our understating of the drought tolerance mechanism. Furthermore, identification of the genetic relationships between FUNAABOR and NERICA rice would further crop improvement programmes of upland rice in Nigeria. This experiment evaluated the efficiency of some SSR primers for polymorphism, determined the genetic basis of drought tolerance in both upland Ofada and NERICA rice and their genetic relationships.

\section{Materials and Methods}

All genomic analysis except DNA quantification was conducted at the Biological Laboratory, Nigerian Institute of Science Laboratory Technology, Samonda, Oyo State, Nigeria. DNA quantification was conducted at National Centre for Genetic Resources and Biotechnology, Oyo State, Nigeria.

\section{Laboratory Experiment}

Four Ofada rice genotypes (FUNAABOR 1 and 2, Straw Gold and Golden Red) and two NERICA (NERICA 7 and 8) rice were selected for genomic 
analysis in the laboratory. Rice varieties were established in an aseptic condition. They were sown in a germination tray $(10 \mathrm{~cm} \times 5 \mathrm{~cm})$ at a temperature of $30^{\circ} \mathrm{C}$ in a sterilised soil for a whole day. Soil sterilisation was achieved through preheating at $100^{\circ} \mathrm{C}$. Seedlings were maintained at ambient temperature in the screen house. Each germination tray consisted of 25 plants at a spacing of $1 \mathrm{~cm} \times 2 \mathrm{~cm}$. From five randomly selected plants per variety $2 \mathrm{~cm}$ was cut with a sterilised scissors from the flag leaf and bulked for genomic analysis at 21days after planting (DAP).

\section{Genomic DNA analysis}

This involved genomic DNA isolation, qualification, quantification, amplification, separation and visualisation of DNA bands. The bulked flag leaves samples were washed in $70 \%$ ethanol and distilled water $\left(\mathrm{dH}_{2} \mathrm{O}\right)$. They were dried on fresh tissue paper. The DNA samples were isolated according to the modified Dellaporta method (Dellaporta et. al., 1983). DNA quality check was conducted by Agarose gel electrophoresis (Sambrook et. al., 1989). The gel was ran at $96 \mathrm{~V}$ for $50 \mathrm{~min}$ and bands were visualized and documented using a gel

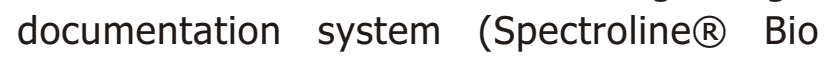
vision $^{\mathrm{TM}}$ UV/White Light Transilluminator TVD1000R/FB Spectrum Corporate, Westboro, New York, USA). The DNA quantification was evaluated using a Thermo Scientific NanoDrop ${ }^{\text {TM }}$ 2000 spectrophotometer (Thermo Fisher Scientific, USA).

\section{SSR markers and PCR amplification}

Sequence of microsatellite primer pairs used in this experiment was downloaded from genome database, Rice Genome Microsatellite Markers (http://www.gramene.org/db/markers.html). Ten primers (generally about 10 base pairs) that were pairs related to drought tolerance were selected based on previous researches. Primers that showed polymorphic banding patterns were selected, while those that displayed monomorphic banding patterns were excluded during optimization. Microsatellite primers with distinct chromosome number were used for final Polymerase Chain Reaction (PCR) amplification.
Information regarding the original source, repeat motifs, primer sequences, expected length, chromosomal localisations and repeat types of the SSRs can be found in the Web database (http://www.gramene.org). The reagents and sterile water were divided into aliquots to minimize the number of sampling errors and to avoid cross contamination. The gel combs and casting trays were washed using 3\% acetic acid. The experiment was repeated until it provided unambiguous results following the recommendations of Newton (1995). The cocktail for PCR amplification was prepared to achieve a reaction mixture of $15 \mu$ l. The reaction in thermal cycler (Eppendorf Master Cycler Gradient) was programmed to reflect the following processes: initial denaturation at $94^{\circ} \mathrm{C}$ for $3 \mathrm{~min}, 35$ cycles of subsequent denaturation at $94^{\circ} \mathrm{C}$ for $1 \mathrm{~min}$ and annealing at $55^{\circ} \mathrm{C}$ for 45 min. Initial Primer extension at $72^{\circ} \mathrm{C}$ for $1 \mathrm{~min}$ and the final Primer extension at $72^{\circ} \mathrm{C}$ for $5 \mathrm{~min}$. The final product was held at $4^{\circ} \mathrm{C}$.

\section{DNA separation and visualisation}

PCR amplified products were separated using Agarose gel electrophoresis. The gel was prepared with $2.5 \%$ agarose that was added to $0.5 \times$ TBE buffer, boiled till the agarose dissolved completely and cooled to $50-60^{\circ} \mathrm{C}$. The staining agent was $1 \mathrm{\mu g} \mathrm{ml}^{-1}$ Ethidium bromide. Agarose gel was poured into gel casting tray and allowed to solidify. After solidification, comb was removed to reveal the loading wells. DNA samples were thoroughly mixed with $3 \mu$ l of loading dye and were loaded into the gel wells. Electrophoresis was conducted at 120 Volts for 1.5 hours and bands were visualised and documented in gel

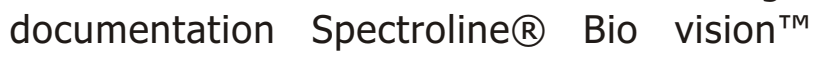
UV/White Light Transilluminator TVD-1000R/FB Spectrum Corporate, Westboro, New York, USA).

\section{SSR data analysis}

The scored gel was subjected to molecular analysis to determine size of amplified bands in base pairs (bp) for each SSR marker, number of effective alleles per locus (*ne), observed number of alleles (*na), genetic diversity $\left(H_{e}\right)$ and Polymorphic Information Content (PIC). The size of most intensely amplified fragments was 
determined by comparing the migration distance of amplified fragments relative to the molecular weight of known size markers (100 bp DNA ladder) using Spectroline ${ }^{\circledR}$ Bio vision ${ }^{\mathrm{TM}}$ UV/White Light Transilluminator TVD-1000R/FB Spectrum Corporate, (Westboro, New York, USA). The number of alleles per locus, major allele frequency, gene diversity and PIC (Polymorphic information content) values were calculated according to Kimura and Crow (1964) and Nei (1973) and the formula developed by $\mathrm{Ni}$ et. al. (2002).

$$
P I C=\frac{1-\sum x^{2} K}{n}
$$

Where, $x_{k}^{2}$ represents the frequency of the $k^{\text {th }}$ allele, $\mathrm{n}$ represents the number of genotypes. Genetic similarity was evaluated from the binary matrix used for the determination of the number and diversity of allele according to Jaccard's similarity coefficient.

\section{Results}

The band size of the primers used were in the range of 98-351 bp (Table 1). RM 72 primer had the least band size (98-198 bp). The highest band size (159-351 bp) was observed in DNA primer RM201. The number of observed allele was in the range 1.5-2.0. Most of the investigated primers had similar number of observed allele except RM 212 (1.5). Similar pattern was observed on the percentage of polymorphic loci. Conversely, the number of effective allele was observed in the range 1.385 (RM 201)-1.92 (RM 212). The degree of heterozygosity was lowest in the primer RM 212 (0.140), the highest was observed in the primer RM 1115 (0.463). Primer RM 72 had the highest polymorphic information content $(0.56)$, while the least (0.35) was observed in RM 36. The highest marker index (3.30) was observed in primer RM316, while the least was observed in RM 212. Similar pattern was repeated on the number of polymorphic loci. The order of DNA fingerprint of the upland rice using RM 316 based on their band size was NERICA 7, Funaabor 1 and Funaabor $2>$ Golden red and NERICA $8>$ Straw Gold (Plate 1). All the upland rice varieties had similar DNA fingerprint on RM 72 except Straw Gold with the least band size (Plate 1).

Table 1: List of the used polymorptic SSR makersincduangname, allele size range, number of observed alleles, effective number of alleles, gene diversity, marker index, polymorphic information content, number of polymorphic loci, percentage polymorphic loci

\begin{tabular}{|c|c|c|c|c|c|c|c|c|c|}
\hline Serial no & $\begin{array}{l}\text { Primer } \\
\text { name }\end{array}$ & $\begin{array}{l}\text { Size } \\
\text { band (bo) }\end{array}$ & ${ }^{*} \mathrm{nag}$ & ${ }^{2} n e$ & *he & $\begin{array}{l}\text { Marker } \\
\text { index } \\
\end{array}$ & PIC & NPL & $\operatorname{PPL}(\%)$ \\
\hline 1 & RM212 & $115 \cdot 125$ & 1.5 & 1.92 & 0.140 & 0.49 & 0.49 & 1 & 50 \\
\hline 2 & RN36 & $189 \cdot 204$ & 2.0 & 1.523 & 0.333 & 1.04 & 0.35 & 3 & 100 \\
\hline 3 & RM3805 & 101-147 & 2.0 & 1.592 & 0.361 & 0.97 & 0.49 & 2 & 100 \\
\hline 4 & RM201 & 159-351 & 2.0 & 1.385 & 0.278 & 1.00 & 0.50 & 2 & 100 \\
\hline 5 & RM1115 & $174-198$ & 2.0 & 1.867 & 0.463 & 1.43 & 0.48 & 3 & 100 \\
\hline 6 & RM316 & 179.253 & 2.0 & 1.769 & 0.429 & 3.30 & 0.47 & 7 & 100 \\
\hline 7 & RM72 & $98-198$ & 2.0 & 1.592 & 0.361 & 1.11 & 0.56 & 2 & 100 \\
\hline
\end{tabular}

${ }^{8}$ na $=$ Observednumber of aleles, ${ }^{*}$ ne $=$ Effective number of alleles, ${ }^{*}$ he $=$ Nei's gene diversty, PIC = Polymorphicinformation content, NPLL Number of polymorphic loci, PPL: Percentage polymorphic loci, bp- base pairs 


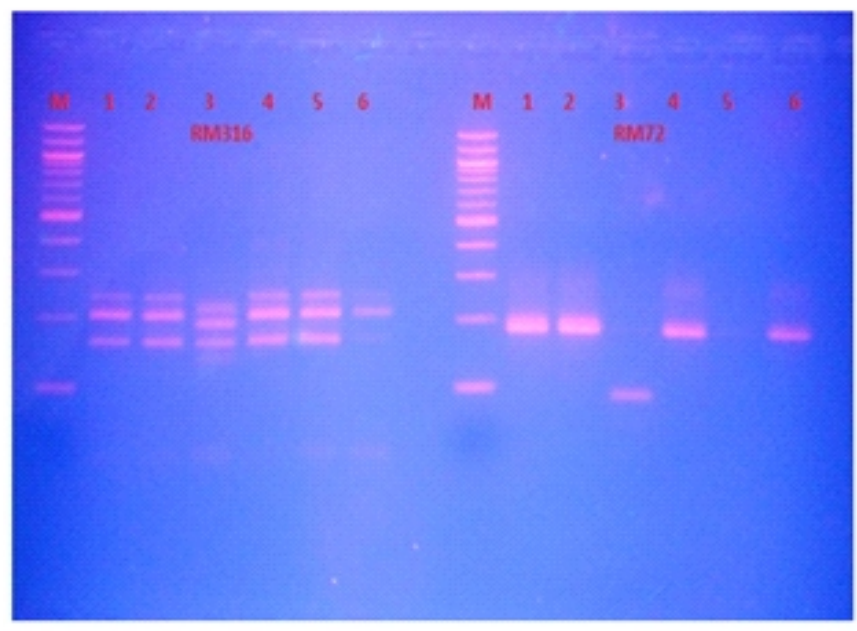

Plate 1: Gel photo of markers RM316 and RM72; M: 100bp gene ladder; No. 1-6 are genotypes used.1: Golden red; 2:NERICA8; 3: Straw gold; 4:NERICA7;5:AUNAABOR1;6:PUNAABOR2.

The genetic relationship among the upland rice varieties were established in the form of their similarities and diversity. Based on the SSR markers it was observed that there was a close genetic similarity between Golden Red and NERICA 8 as expressed in their similarity coefficient (0.95) (Table 2). This was closely followed by FUNAABOR 2 (0.68), FUNAABOR 1 (0.63) and NERICA 7 (0.63). Straw Gold was genetically diverse from Golden Red but genetically similar to FUNAABOR 2 (0.63).
NERICA 8 was observed to be genetically similar to FUNAABOR 2 (0.63), however, Straw Gold was observed to be the genetically least related to NERICA 8. In terms of genetic similarity a converse pattern was observed between Straw Gold and NERICA 7 (0.22). NERICA 7 was observed to be genetically similar to FUNAABOR 1 (0.90) and least related genetically with FUNAABOR 2 (0.59). The genetic similarity between FUNAABOR 1 and FUNAABOR 2 was observed to be moderate (0.59).

Table 2: Similarity coefficient among studied genotypes based on SSR markers

\begin{tabular}{|c|c|c|c|c|c|c|}
\hline & GRD & NERICA8 & $\overline{\text { STG }}$ & NERICA7 & FUNABOR1 & FUNABOR2 \\
\hline GRD & 1.00 & & & & & \\
\hline NERICA8 & 0.95 & 1.00 & & & & \\
\hline STG & 0.40 & 0.36 & 1.00 & & & \\
\hline NERICA7 & 0.63 & 0.59 & 0.22 & 1.00 & & \\
\hline FUNABOR1 & 0.63 & 0.59 & 0.31 & 0.90 & 1.00 & \\
\hline FUNABOR2 & 0.68 & 0.63 & 0.63 & 0.59 & 0.59 & 1.00 \\
\hline
\end{tabular}

\section{GRD-Golden Red, STG-Straw Gold}

\section{Discussion}

Genetic crop improvement programmes leverages on the genetic diversity of cultivated crops. Characterisation of crops for genetic diversity and similarities could be conducted at all levels of its organisation. The choice of molecular characterisation of the genetic identity and relationships among the upland rice genotypes could be premised on the observation of Ramadan et. al. (2015). He asserted that DNA markers were unaffected by the environmental factors. Molecular characterisations of upland rice genotypes (Ofada) together with NERICA rice for drought tolerance would ensure their genetic identity and form basis for further breeding efforts in the country. Water deficit remains a major production constraint in the establishment of both upland and lowland rice. Though comparatively the area under the cultivation of upland rice is lesser than that of the lowland for most of the resource-challenged farmers in the tropical areas it remains one of the major alternative in rice production. 
Efficiency of selected primers was evaluated for informativeness based on some genetic parameters. The differences in the primer parameters suggested variation in the efficiency of these primers in the detection of genetic variation of the rice genotypes. It was observed that primer RM 212 had the least number and percentage polymorphic loci. This could have been associated with reduced number of allele per loci. This pattern could also have been implicated in the reduced number of marker index and genetic diversity index observed in this primer. However, the observed high PIC in this primer could be linked with the high number of effective allele per loci observed in primer 212, despite the reduced efficiency of other primer parameters indicted earlier. Lapitan et. al. (2007) observed that there is a direct and positive relationship between the numbers of allele per loci with PIC. This experiment was able to indicate that the observed relationship could be linked more to the number of effective allele per loci than just the number of allele per loci. Other opinions were expressed by Nagy et. al. (2012), that high heterozygosity is responsible for high value of PIC. The observed differences in our opinion may not be unconnected with the need to factor biological character of species, phylogeny and their ontogeny in the their genetic evaluation (Chesnokov and Artemyeva, 2015). The efficiency of RM 316 primer could be associated with the higher marker index. This parameter had been observed to be linked with other efficiency parameters of primers, such as PIC and number of polymorphic loci (Mandal et. al. 2016). In our own study it was associated with both the number and percentage of polymorphic loci. These primer parameters could be linked with the number of allele per loci as indicated in this study. Primer RM 72 had the highest PIC. This marker could be considered highly informative based on the assessment classification proposed by Ramadan et. al. (2015), while others could be interpreted to be slightly informative. This parameter was linked to high percentage of polymorphic loci and number of allele per loci than what was observed in RM 212.

Based on the efficiency of the primers investigated it could be suggested that RM 316 and RM 72 could be used in the study on DNA fingerprinting of these upland rice genotypes since they provide more polymorphism than others used in this study. RM 72 primer is associated with QTL brt8-12 (Qu et. al., 2008). This could have suggested that upland rice cultivar Golden Red, NERICA 8 and NERICA 7 exhibited more QTL brt8-12 based on their gene ladder than others on the RM 72 primer. This QTL had been linked with the basal root thickness in rice (Qu et. al., 2008). He further highlighted that there is a close correlation between basal root thickness and the maximum root length at all growth stages. The maximum root length is associated with the root fresh and dry weight and the root volume (Qu et. al., 2008). This morphological character could have been linked with drought resistance.

A well developed root system is associated with water and nutrient uptake. NERICA 7, FUNAABOR 1 and FUNAABOR 2 occupied the highest DNA ladder in the marker M 316 suggesting the high presence of the QTL QRsf9. Yue et. al. (2006) reported that QTL QRsf9 is linked with relative spikelet fertility under moisture stress in rice at the reproductive growth stage. It could be inferred that these upland rice genotypes could be selected to attain reproductive fitness under water deficit. Crop improvement could be attained with increased genetic variation. Similarity between NERICA 8 and Golden Red cultivar suggested that either of this could be used to support breeding programme. Those that displayed more genetic variation would have been better explored for genetic crop improvement under different abiotic stress factors. Varied mechanisms have been reported in rice that would ensure their adaptation to water deficit depending on the cultivar, timing and intensity of water deficit.

The well developed root system observed in NERICA 8, NERICA 7 and Golden Red could be explored especially for the avoidance mechanism in rice. Nassir et. al. (2017) observed that NERICA 7, 12 and 16 when subjected to soil moisture deficit at the vegetative growth stage had significantly higher grain yield than others among 16 released NERICA varieties. He reported that such could have been linked to 
their root growth under water deficit. Similar pattern was observed in NERICA 8. However, the similarities in the development of this root system in the aforementioned upland rice varieties indicted that any of the genotypes could be used as a donor in the development of the phenotypic trait.

\section{Conclusion}

DNA primers RM 316 and RM 72 were selected based on markers index and polymorphic information content respectively. These primers were reported to be linked with drought tolerance (root architecture and relative spikelet fertility) in rice under water deficit at the reproductive growth stage. For crop improvement towards drought tolerance exploration of genetic variation for varied tolerance mechanism is a better option. Upland rice cultivars that had similar genetic relationship (Golden Red, NERICA 7 and NERICA 8) are better utilised with those of dissimilar sources (Straw Gold, FUNAABOR 1 and FUNAABOR 2) to ensure genetic variation.

\section{Acknowledgements}

The management and staff of Nigerian Institute of Science Laboratory Technology, Samonda, and National Centre for Genetic Resources and Biotechnology are hereby acknowledged for their support during the course of this project.

\section{References}

Belder, P., Bouman, B. A. M., Cabangon, R., Guoan, L., Quilang, E. J. P., Yuanhua, L. and Tuong, T. P. (2004). Effect of water-saving irrigation on rice yield and water use in typical lowland conditions in Asia. Agric. Water Mgt. 65(3), $193-210$.

Bouman, B. A. M. (2007). A conceptual framework for the improvement of crop water productivity at different spatial scales. Agric. Sys. 93(1), $43-60$.

Chesnokov, Y. V.and Artemyeva, A. M. (2015). Evaluation of the measure of polymorphism information of genetic diversity. Ñåëüñêĩôi̧y̌éẽòôåííày áèîëîãèÿ, (5 (eng)). $\mathrm{R}$ e $\mathrm{t} \mathrm{r}$ i e $\mathrm{v}$ e d $\mathrm{f} \mathrm{r}$ o m http://cyberleninka.ru/article/n/evaluation-ofthe-measure-of-polymorphism-information-ofgenetic-diversity
Dellaporta, S. L., Wood, J. and Hicks, J. B. (1983). A plant DNA minipreparation: version II. Plant Mol. Biol. Rep. 1(4), 19 - 21.

Diagne, A., Alia, D., Amovin-Assagba, E., Wopereis, M. ., Saito, K.and Nakelse, T. (2013). Farmers perception of biophysical constraints to rice production in sub-sahara Africa and potential impact of research. In Realising Africa Rice Promise (pp. 4648). CABI.

Fagbade, S. (2006). Yield gaps and productivity decline in rice production. International Rice Communication/FAO.

Idris, A., Rasaki, K., Hodefe, O. J.and Hakeem, B. (2013). Consumption pattern of Ofada rice among civil servants in Abeokuta Metropolis of Ogun State, Nigeria. J. Biol., Agric. and Healthc. 3(6), $106-112$.

Jones, M. P., Dingkuhn, M., Aluko, G. K., Semon, M. (1997). Interspecific Oryza sativa L. $\times \mathbf{0}$. glaberrima Steud. progenies in upland rice improvement. Euphytica, 94(2), 237246.

Kimura, M. and Crow, J. F. (1964). The number of alleles that can be maintained in a finite population. Genetics, 49(4), 725 - 738.

Lapitan, V. C., Brar, D. S., Abe, T.and Redoña, E. D. (2007). Assessment of genetic diversity of Philippine rice cultivars carrying good quality traits using SSR markers. Breed Sci. 57(4), 263 270.

Linares, O. F. (2002). African rice (Oryza glaberrima): History and future potential. Proc. Natl. Acad. Sci.U.S.A. 99(25), 1636016365. https://doi.org/10.1073/pnas.252604599

Liu, M., Xu, Y., He, J., Zhang, S., Wang, Y. and Lu, P. (2016). Genetic diversity and population structure of Broomcorn Millet (Panicum miliaceum L.) cultivars and landraces in china based on microsatellite markers. Int. J. Mol. Sci. 17(3), 370. 
Mandal, R., Nag, S., Tarafdar, J.and Mitra, S. (2016). A comparison of efficiency parameters of SSR markers and genetic diversity analysis in Amorphophallus paeoniifolius (Dennst.) Nicolson. Braz. Arch. Biol. Technol. 59,1 - 7.

Nagy, S., Cernak, I., Gorji, A. ., Hegedus, G.and Taller, J. (2012). PICcalc: An online program to calculate polymorphic information content for molecular genetic studies. Biochem. Genet. 50, $670-672$.

Nassir, A., Akinade, A., Adewusi, K. and Olagunju, S. O. (2017). Response of NERICA rice genotypes to varied soil moisture levels and implications fro drought tolerance and grain yield. Afr. J. Sci. Nature, 4, 89 - 97.

Nei, M. (1973). Analysis of gene diversity in subdivided populations. Pro. Natl. Acad. Sci. U.S.A, 70 (12), 3321 - 3323.

Newton, K. (1995). Aberrant growth phenotypes associated with mitochondrial genome arragements in higher plants. In: C. Levings and I.K (Eds.), The molecular biology of plant mitochondria (pp. 585 - 596). Dordrecht, the Netherlands: Kluwer academic publishers.

Ni, J., Colowit, P. M.and Mackill, D. J. (2002). Evaluation of genetic diversity in rice subspecies using microsatellite markers. Crop Sci. 42(2), $601-607$.

Qu, Y., Mu, P., Zhang, H., Chen, C. Y., Gao, Y., Tian, Y. and Li, Z. (2008). Mapping QTLs of root morphological traits at different growth stages in rice. Genetica, 133(2), 187 - 200.
Ramadan, E. ., Elmoghazy, A.and Mowafi, H. . (2015). Molecular markers based genetic diversity analysis for drought tolerance in rice (Oryza sativa, L) using SSR markers. Int J Sci Res. Agric.Sci. 2, 137 - 146.

Sambrook, J., Fritsch, E. and Maniatis, T. (1989). Molecular cloning: A laboratory manual (2nd ed.). Cold Spring Habor, NY: Cold Spring Habor Laboratory Press.

Semagen, K., Ndjiondjop, M.and Cissoko, M. (2006). Microsatellite and agronomic traits for assessing genetic relationship among 18 new rice for Africa (NERICA) varieties. Afri J. Biotech. $5,800-810$.

Showemimo, F., Gregorio, G., Olowe, V. I.O., Ukwungwu, M.N., Maji, A. T., Adigbo, S.O., Olaoye, O.J., Akintokun, P.O., Bodunde, J.G., Idowu, OT.H and Awe, C.A (2011). Varietal release: release of two dual purpose ofada rice varieties (FUNAABOR 1 and FUNAABOR-2) by the Federal University of Agriculture, Abeokuta (FUNAAB). J. Agric. Sci. Env. 11(2), 122 - 123.

Yeo, M. E., Cuartero, J., Flowers, T. J.and Yeo, A. R. (1997). Gas Exchange, Water Loss and Biomass Production in Rice and Wild Oryza Species in Well-Watered and Water-Limiting Growth Conditions. Plant Biol. 110(1), 32 - 42.

Yue, B., Xue, W., Xiong, L., Yu, X., Luo, L., Cui, K.and Zhang, Q. (2006). Genetic basis of drought resistance at reproductive stage in rice: separation of drought tolerance from drought avoidance. Genetics, 172(2), 1213 - 1228. 